\title{
THE DIAGNOSIS OF DELIRIUM IN 80 EMERGENCY UNIT PATIENTS
}

\author{
AFONSO CARLOS NEVES*, RICARDO DE CASTRO CINTRA SESSO**, \\ HENRIQUE BALLALAI FERRAZ***, SILVIO FRANCISCO****, JOÃO BAPTISTA DOS REIS-FILHO*****
}

\begin{abstract}
We evaluated the initial and final diagnosis of 80 patients with delirium arriving at the emergence unit of a university hospital in a large Brazilian city over a period of 30 months up to December 1991. The diagnosis was based on the DSM-IIIR criteria. Patients with a known history of head trauma or epileptic seizure and patients younger than 13 years were excluded. Only patients with a disease of up to 7 days were included.The patients were subdivided into four etiologic groups: vascular; associated with the use of alcohol; infectiousparasitic; miscellaneous. The results showed a rate of correct diagnosis ranging from 65 to $80 \%$ with the use of kappa test (standard good to excelent). Sensitivity, specificity, positive predictive and negative predictive values had results showing different conditions for initial diagnosis in each group. This study can help the initial diagnosis of delirium and the choice for diagnostic testing.
\end{abstract}

KEY WORDS: delirium, diagnosis, acute confusional state.

\section{Diagnóstico de delirium em 80 pacientes atendidos no pronto socorro}

RESUMO - Nós avaliamos o diagnóstico inicial e final de 80 pacientes com delirium que chegaram ao Pronto Socorro do Hospital São Paulo, Universidade Federal de São Paulo, no período de 30 meses até dezembro-1991. O diagnóstico foi baseado nos critérios do DSM-IIIR. Os pacientes com história de trauma de crânio, crises epiléticas e idade inferior a 13 anos foram excluídos. Os pacientes foram subdivididos em quatro grupos etiológicos: vascular; associado ao uso de álcool; infecto-parasitário; miscelânea.Os resultados mostraram porcentagem de acerto entre $65-80 \%$. O teste de kappa mostrou-se entre bom e excelente. $\mathrm{O}$ resultado da sensibilidade, especificidade, valor preditivo positivo e negativo mostraram diferentes condições no diagnóstico inicial de cada grupo. Este estudo pode ajudar na escolha de um teste para o diagnóstico inicial de delirium.

PALAVRAS-CHAVE: delirium, diagnóstico, estado confusional agudo.

Delirium is a quite common syndrome but is often underestimated. The synonymy of this disease includes about thirty other terms. The first scientific description of delirium was probably made by Hippocrates. He used the word phrenitis, derived from phrenes, a word used to mean mind and also the muscle diaphragm. The word delirium was first used by Celsius, in the first century before Christ $^{1}$. Great progress in the knowledge of acquired cognitive disturbances was first made in the nineteenth century. The linkage between brain and behavior was assumed to exist in a modern scientific meaning after the description of a left brain lesion associated with aphasia by Broca. Description of neurosyphilis, Huntington's chorea and Pick's disease were made by other authors. In 1906, Alzheimer described signs of neuronal degeneration in the brain of a woman with a progressive memory disorder ${ }^{2}$.

Department of Neurology and Neurosurgery, Escola Paulista de Medicina, Universidade Federal de São Paulo (UNIFESP): *M.D., Ph.D., Attendant Neurologist, São Paulo Hospital (SPH/UNIFESP); **M.D., Ph.D., Professor of Nephrology, Epidemiologist Research, UNIFESP; ***M.D., Ph.D., Attendant Neurologist, SPH/ UNIFESP; ****M.D., Attendant Neurologist, SPH/UNIFESP; *****M.D., Ph.D., Professor of Neurology, UNIFESP. Aceite: 11-fevereiro-1998.

Dr. Afonso Carlos Neves - Rua Albano Eugênio Dahmer 33, Granja Viana - 06700-000 Cotia SP - Brazil. FAX 5511549 2127. E-mail: cj0333623043@originet.com.br 
In terms of nosologic classification, it was a long way from 1793 to 1940 with a large variety of names for this pathological condition, ranging from a psychiatric to an organic disorder. Pinel included the disorder into the "idiotism" category. Esquirol described this as "acute idiotism". Georget and Delasiany called it "acquired stupidity". In 1870, Hood reported seven cases of senile delirium and concluded that it could be reversible with the treatment of its cause.In 1895 Chaslin was the first to use the term "confusional syndrome". Régis considered this condition to be a psychotic manifestation of endogenous and exogenous intoxication. Marchand, Courtois and Toulouse considered confusional alterations as a reaction of the nervous system to several aggressions, with inflammatory lesions as a pathological substrate ${ }^{3-5}$. The elaboration of the DSM-I (Diagnostic and Statistical Manual of Mental Disorders) in 1952 marked the beginning of the attempt to unify the diagnosis of delirium. So far, we have DSM-IIIR and DSM-IV and there is a tendency to better unify this diagnosis, although several doctors that do not use this criterion in practice.

Delirium is a relatively common disturbance in hospitalized geriatric patients, although this has not been extensively investigated ${ }^{6-8}$. The incidence of delirium in hospitalized patients is about 10 to $15 \%$ and this proportion increases to 30 to $50 \%$ in hospitalized geriatric patients ${ }^{9}$. There is no study about the occurrence of delirium in Brazilian hospitals, including emergency units and we do not know how clinicians or specialists deal with this disease.

The objective of this study was to evaluate the diagnosis of delirium in the emergency unit of a hospital in a large Brazilian city. This evaluation includes the first clinical etiological supposition and what tools helped to elucidate the diagnosis.

\section{MATERIAL AND METHODS}

We evaluated the initial and the final diagnosis of 80 patients with delirium arriving at the emergency unit of a university hospital in a large Brazilian city over a period of 30 months up to December 1991. This number corresponded to a $70 \%$ of all cases with suspected delirium received at the Emergency Unit of this hospital. The diagnosis of delirium was based on DSM-IIIR ${ }^{10}$ criteria which are:

A. Reduced capacity to pay attention to external stimulation or to change the attention to other new external stimulation. B. No organized thinking.

C. Two of this conditions: 1. reduction of consciousness level; 2. perceptive disturbances: false interpretations, delusions, hallucinations; 3 . disturbance of the sleeping cycle; 4. improvement or reduction of psychomotor activity; 5 . time, spatial or self disorientation; 6. memory disturbance.

D. Short duration of disease (hours or days) with fluctuation during the day.

E. Or 1 or 2: 1. evidence from history, physical examination or laboratory tests of an organic etiology; 2. a presumable organic factor.

Patients with a known history of head trauma or epileptic seizure and patients younger than 13 years were excluded. Only patients with a disease of up to 7 days were included. There were 57 men and 23 women.

The patients were subdivided into four etiologic groups: vascular, associated with the use of alcohol, infectious-parasitic and miscellaneous group. In the situation of several simultaneous etiological diagnoses we called the etiology multiple causes and included these cases in the miscellaneous group.

The solicitation of laboratory, radiological test and initial diagnosis of delirium was first established by the emergency staff without our influence. We simply applied our protocol to include the patient in the study or not.

Statistical Analysis

1. The kappa test was applied to the entire group of patients to verify the degree of agreement between initial diagnosis and final diagnosis, divided into the four groups of diagnosis ${ }^{11}$. The interpretation of the degree of concordance was as follows: 0 to 0.4 poor; 4 to 0.75 good; 0.75 to 1 excellent.

2. The sensitivity, specificity, positive predictive value (PPV) and negative predictive value (NPV) were observed in the four groups according to the following definitions: Sensitivity corresponded to the proportion of individuals with the studied disease who had a positive initial diagnosis and positive final diagnosis in each group; Specificity corresponded to the proportion of individuals with the studied disease who had a negative initial diagnosis and a negative final diagnosis in each group ${ }^{12}$

The PPV corresponded to the chance of an individual with the studied disease to have an initial diagnosis equal to the final diagnosis in each group. 
The NPV corresponded to the chance of an individual without the studied disease to have an initial diagnosis not equal to the final diagnosis, in each group.

\section{RESULTS}

Fifteen of the 80 cases studied were not possible to do a specific etiologic hypothesis in the admission and their final diagnosis are shown on Table 1. The final diagnosis of the other 65 cases are shown on Tables 2 and 3. The rate of correct diagnosis for the 80 cases was $65 \%$ ( 52 cases). If we consider only the 65 patients with a specific etiologic initial diagnosis the rate of correct diagnosis was $80 \%$.

Table 4 shows diagnosis by groups of diagnosis and the kappa test was applied. Table 5 shows the sensitivity and specificity for the initial diagnosis of delirium in the four groups.

The age ranged from 13 to 78 years in 80 patients. Table 6 shows the frequency of patients in age groups.

Table 1. Final diagnosis in patients with no initial specific etiologic hypothesis.

\begin{tabular}{lc}
\hline Final diagnosis & $\mathrm{N}^{\circ}$ of cases \\
\hline Ischemic cerebrovascular disease & 2 \\
Neurosyphilis & 1 \\
Viral encephalitis & 2 \\
Primary hypoparathyroidism & 1 \\
Multiple causes & 6 \\
Post-ictal state & 1 \\
Alcohol withdrawal & 1 \\
Confusional migraine & 1 \\
Total & 15 \\
\hline
\end{tabular}

Table 2. Cases with a correct etiologic diagnosis.

\begin{tabular}{lc}
\hline Diagnosis & $\mathrm{N}^{\circ}$ of cases \\
\hline Ischemic cerebrovascular disease & 14 \\
Hemorrhagic cerebrovascular disease & 5 \\
Ruptured cerebral aneurysm & 2 \\
Alcohol withdrawal & 14 \\
Wernicke-Korsakoff syndrome & 5 \\
Pathological drunkenness & 1 \\
Hepatic encephalopathy & 1 \\
Viral encephalitis & 4 \\
Neurocysticercosis & 1 \\
Acute meningoencephalitis & 3 \\
Pos-ictal state & 1 \\
Exogenous intoxication & 1 \\
Total & 52 \\
\hline
\end{tabular}

Table 3. Cases with an incorrect etiological diagnosis.

\begin{tabular}{ll}
\hline Initial hypothesis & Final diagnosis \\
\hline Subarachnoid hemorrhage & Multiple causes \\
Wernicke-Korsakoff syndrome & Ischemic cerebrovascular disease \\
Ischemic cerebrovascular disease & Brain tumor \\
Brain tumor & Exogenous intoxication \\
Brain tumor & Neurocysticercosis \\
Viral encephalitis & Meningotuberculosis \\
Exogenous intoxication & Cerebral aneurysm \\
Viral encephalitis & Brain abscess \\
Hemorrhagic cerebrovascular disease & Ischemic cerebrovascular disease \\
Meningoencephalitis & Posttrauma hemorrhage \\
Ischemic cerebrovascular disease & Brain metastasis \\
Ischemic cerebrovascular disease & Multiple causes \\
Brain tumor & Viral encephalitis \\
\hline
\end{tabular}


Table 4. Diagnosis by groups.

\begin{tabular}{lccccc}
\hline & \multicolumn{5}{c}{ Final diagnosis } \\
\cline { 2 - 6 } Initial Diagnosis & Vascular & Alcoholic & Infectious-Parasitic & Miscellaneous & Total \\
\hline Vascular & 22 & 0 & 0 & 4 & 26 \\
Alcoholic & 1 & 21 & 0 & 0 & 22 \\
Infectious-Parasitic & 0 & 0 & 10 & 1 & 11 \\
Miscellaneous & 3 & 1 & 5 & 12 & 21 \\
Total & 26 & 22 & 15 & 17 & 80 \\
\hline
\end{tabular}

The kappa test yielded the following result: kappa coefficient $=0.746$; standard error $=0.059 ; \mathrm{z}$-statistic $=12.596$; $\mathrm{z}$ critical is 1.96 for alpha $=0.05$.

Table 5. Sensitivity, specificity, positive predictive value (PPV) and negative predictive value (NPV) in the four groups (percent).

\begin{tabular}{|c|c|c|c|c|c|c|}
\hline Group & Sensitivity & Specificity & PPV & NPV & & \\
\hline Vascular & 84.6 & 92.5 & 84.6 & 92.5 & $21-30$ & $\begin{array}{c}5 \\
10\end{array}$ \\
\hline & & & & & $31-40$ & 16 \\
\hline Alcohol & 95.4 & 98.2 & 95.4 & 98.2 & $41-50$ & 12 \\
\hline Infectious-parasitic & 66.6 & 98.4 & 90.9 & 92.7 & $\begin{array}{l}51-60 \\
61-70\end{array}$ & $\begin{array}{l}16 \\
14\end{array}$ \\
\hline Miscellaneous & 70.5 & 85.7 & 57.0 & 91.5 & $71-80$ & 7 \\
\hline
\end{tabular}

\section{DISCUSSION}

The formulation of a diagnostic hypothesis of delirium is complex and involves all the sources of knowledge of the observer; this diagnosis includes the organic and psychological aspects of the patient. The diagnosis of psychiatric problems are usually misled at emergency units and the DSMIIIR may be a useful tool to identify such cases ${ }^{13}$. On the other hand, psychiatric patients have a kind of stigma which prevents the formulation of organic diagnoses by doctors who are not psychiatrists. Crawshaw reported the case of a schizophrenic patient with a symptomatology that was considered by several doctors to be associated with the basal psychiatric disease; the patient died of a fungal disease in an advanced stage ${ }^{14}$.

The concept of normality has also implications going beyond the clinical and psychiatric diagnosis, including social, cultural and philosophical aspects. Monney conducted a large study in Lausanne on file cards of psychiatric consultations covering a period of 23 years, and observed the notation "without apparent psychiatric symptomatology"15. He noted a variation of this reference over time and attributed the changes in the diagnostic criteria to different codification or circumstances that allowed or limited the use of that expression.

The above - attributing excessive value to the clinical diagnosis, to psychiatric diagnosis or to normality - one must equilibrate the syndromic diagnosis of delirium. In a search for objectivity in this diagnosis, the authors who studied this disorder continue to point out the necessity to think about these different influences ${ }^{16-18}$.

Like Freudenburg, when we have to make an assumption in a situation of high consensus, large experience and few obstacles, this assumption has less probability of error; conversely, with low consensus, little experience and many obstacles, the probability of error increases greatly ${ }^{19}$. The author says that the reflection about scientific facts, seen independently of social implications, has low error risk. We can compare this with the situation of the Brazilian social environment, where the social influences can impair the scientific investigation and thus perhaps confuse the focus of the actual diagnosis. 
The diagnostic decision has been studied in several circumstances in other countries under probably ideal conditions ${ }^{20}$. In Brazilian circumstances this is still an open field for investigation.

Although there is a reasonable consensus about the use of DSM-IIIR criteria, some authors believe that these criteria are vague, and suggest studies for more detailed and less schematic classifications ${ }^{21}$. Lipowski proposed the designation "transitory cognitive disorders" for delirium and pseudodelirium; the term pseudodelirium was used by this author to name the situations analogous to the pseudodementia, i.e., social conditions that induce to the false diagnosis of delirium ${ }^{1}$. Several authors call attention to the need to train physicians and nurses to diagnose delirium ${ }^{22,23}$.

In this study we evaluated 80 patients, ranging in age from 13 to 78 years, whose distribution showed a greater number of cases between 31 and 40 years old and between 51 and 60 years old; this can be correlated with alcohol in the former and with vascular disease in the latter; also more than $50 \%$ of delirium cases seen at the emergency unit were under fifty years old. This demonstrates how this disturbance is important and how limiting this condition is for individuals of productive age and how this fact is harmful to society.

Our study focused on an age range that is commonly seen in emergency units of Brazil. The international literature works more often with elderly patients ${ }^{24-26}$.

It is interesting to remember that we had no cases of AIDS (acquired immunodeficiency syndrome) in our series probably because we have limited the time of disease to 7 days; we have observed some cases of AIDS that had more than one week of delirium and so they were not included in the protocol.

Some authors have emphasized the fact that perhaps delirium is more common that we suppose and that it does not receive enough attention from researchers ${ }^{27}$.

The initial diagnosis presented an efficacy of $65 \%$ to $80 \%$. The kappa test showed a result ranging from good to excellent. These data demonstrate that the initial clinical evaluation, before any subsidiary examination, can lead to the diagnosis of a large number of cases of delirium; nevertheless, these data do not mean that we do not need further investigation. We can take a better look at this situation by studying each separate group. In the alcohol group there was $95.4 \%$ sensitivity, 98\% specificity, 95.2\% PPV and 98.3\% NPV. These data suggest that in the alcohol group there is almost no need for further investigation. In the infectious-parasitic group there was $66.6 \%$ sensitivity, 98.4\% specificity, $90.9 \%$ PPV and $92.7 \%$ NPV. In this situation sensitivity was not so good. In the vascular group there was $84.6 \%$ sensitivity, $92.5 \%$ specificity, $84.6 \%$ PPV and $92.5 \%$ NPV. Sensitivity and PPV were the weaker points. In the miscellaneous group there was $70.5 \%$ sensitivity, 85.7 specificity, $57 \%$ PPV and $91.5 \%$ NPV. Only NPV was good. On the basis of these data, perhaps the infectious-parasitic group and the vascular group sometimes need some kind of investigation, while in miscellaneous group, for all cases, is necessary subsidiary examination.

Today there is a worldwide necessity to use resources in a rational manner, especially in developing countries. The great advance in investigative methods has excited excessively the doctors and relegated clinical evaluation to a less important level. Some authors have emphasized the meaning of the traditional clinical investigation, despite the technological progress ${ }^{28}$. Durbridge et al. noted that some groups of doctors consider an initial screening when a patient enters the hospital with the intention to reduce expenses and promote better patient care ${ }^{29}$. The authors observed 500 patients with preliminary screening compared to a control group and concluded that the tests increased the hospital expenses without benefits for the patient.

Educational and administrative strategies in teaching hospitals can drastically reduce the use of subsidiary examination, with less discomfort for the patient, no impairment of care and with an important reduction of expenses ${ }^{30,31}$. Thurow reported that in The United States there is a great preoccupation with the growing expenses in health and thinks that this problem needs to be solved more in an ethical than in an economical way ${ }^{32}$. 
Kassirer considers that the absolute certainty of diagnosis is unattainable. He says that the task of doctors is not to achieve certainty but to reduce uncertainty in order to make the best possible therapeutic decision. In the last 20 years the subsidiary examinations have increased the ability to reduce the diagnostic uncertainty ${ }^{33-34}$. Factors such as false positive or false negative results may lead to a wrong reasoning. An inordinate zeal for certainty has led to unnecessary examinations such as a test used simply to confirm another without changes in treatment. Excessive confidence in some probabilities can also induce to errors. The uncertainty over a probability, also called ambiguity, may be due to scarce or irrelevant information, or when expert opinions are conflicting. Numbers and percentages cannot be the unique parameters to determine medical conduct.

Black and Ling observed that one can have a false impression about some advances in subsidiary diagnosis that perhaps do not represent a real benefit for the patient ${ }^{35}$. They emphasize two points: one point is when the early diagnosis by some investigation does not make a difference in therapeutic and just brings on more suffering and expenses for the patient; another point is when a test reveal an occult disease that become a worry to the patient and some times it brings on early therapeutic without necessity. These authors consider the "wait and see" important to be remembered mainly in geriatric patients.

Gifford et al., studying diagnostic reasoning in neurology, observed that the decision-making process is today more complex than it was before, because there are several factors, including social factors of the physician himself such as salary or defensive medicine ${ }^{36}$. It is difficult to examine these conditions in the present study, but in a developing country, in an emergency situation, we know that this bias probably does occur.

Francis et al. studied 229 hospitalized geriatric patients looking for delirium and its etiology ${ }^{37}$. Of these, 50\% had delirium, 30\% had a defined etiology, 20\% had a probable etiology and $44 \%$ had several associated etiologic factors. The most frequent causes were: fluid and electrolytic disorders; infections; drug toxicity and metabolic disorders. The authors emphasize that although cerebral CT (computer tomography) scan and cerebrospinal fluid examinations are recommended in the diagnosis of delirium, history and clinical examination with blood studies were more important for etiology identification.

Kolbeinsson and Jonsson studied 331 patients aged more than 70 years admitted to the emergency unit of a general hospital in Reykjavik, Iceland, and found $14 \%$ of cases with delirium ${ }^{38}$, the main causes were cardiac failure, stroke and sepsis.

Cole and Primeau studied the prognosis of delirium by meta-analysis of articles published from 1980 to 1992, they found that in the elderly delirium appears to have a poor prognosis, however, the presence of other factors such as dementia and physical illness may confound this conclusion. Koponen and Riekkinen studied 70 elderly patients and found the most common etiologies to be stroke, infections and metabolic diseases ${ }^{40}$.

Farrell and Ganzini studied misdiagnosing delirium as depression in medically ill elderly patients; $41.8 \%$ of 67 patients with depression were found to be delirious ${ }^{41}$. The authors say that is necessary to consider the possibility of delirium in hospitalized elderly patients who appear to be depressed.

Kishi et al. studied the presence of delirium in 238 patients admitted in an emergency room ${ }^{42}$. Thirty- eight patients (16\% ) developed delirium. Of 325 consecutive admissions, 238 patients were identified for inclusion in the study. They found no significant difference for any specific disease category to develop delirium in a critical care unit.

Our study considered only cases with delirium in the emergency unit. We did not find any other equivalent report in the literature. 
In developing countries such as Brazil, many times it is not possible to obtain a CT scan or a CSF examination in time. Thus we think it is helpful to keep in mind this division of delirium into four groups: vascular group; alcohol group; infectious-parasitic group and miscellaneous group. This is useful in patients more than 12 years old and with up to seven days of disease, except cases of cranial trauma and epileptic seizures.

About the use of subsidiary tests to find the etiology of delirium, we propose the following: 1 . alcohol group - no need for tests; 2 . vascular group - some tests are necessary - mainly head CT scan; 3. infecto-parasitic group - some tests are necessary - mainly CSF or head CT scan; 4. miscellaneous group - always needs investigation - head CT scan, CSF or blood tests.

\section{CONCLUSIONS}

On the basis of this study we may suggest that a patient with delirium syndrome, aged more than 12 years, with less than 7 days of disease, except cases of cranial trauma and epileptic seizures, can be assigned to one of four groups of initial diagnosis: vascular; alcoholic; infecto-parasitic and miscellaneous. For further investigation we may indicate cerebral CT scan for the vascular group, CSF for the infecto-parasitic and general tests for the miscellaneous group and no subsidiary tests for the alcohol use group. It is very important to keep in mind that, by the dynamic of the disease process, sometimes the symptomatology changes, taking the diagnosis from one field to another, requiring other tests

Delirium is a mirror of social and health problems in developing countries. To prevent the social consequences of delirium is to prevent alcoholism and vascular disturbances such as arterial hypertension, and other factors such as infectious and parasitic diseases.

\section{REFERENCES}

1. Lipowski ZJ. Delirium in older adults. Adv Psychosom Med 1989;19:1-16.

2. Odenheimer GL. Acquired cognitive disorders of the elderly. Med Clin North Am 1989;73:1383-1411.

3. Deniker P, Colonna L, Gaussel JJ. Syndrome confusionnel, étude sémiologique. Rev Med Interne 1971;27:1735-1738.

4. Lipowski ZJ. Transient cognitive disorders (delirium, acute confusional states ) in the elderly. Am J Psychiatry 1983;140:1426-1436.

5. Olivennes A. Propositions pour une nouvelle classification des syndromes confusionnels. Ann Méd Psychol 1989; 147:679-684.

6. Bayne JRD. Management of confusion in elderly persons. Can Med Assoc J 1978;118:139-141.

7. Berthaux P. Les troubles de la vigilance et les états confusionnels du sujet âgé. Le point de vue du gériatre. Sem Hôp Paris 1986;62:2801-2802.

8. Taylor D, Lewis S. Delirium. J Neurol Neurosurg Psychiatry 1993;56:742-751.

9. Goldman LS. Delirium. In Flaherty, Channon, Davis (eds). Psychiatry: diagnosis and therapy. New York: Appleton \& Lange, 1989.

10. Diagnostic and Statistical Manual of Mental Disorders, DSMIII-R (3- Ed revised). Washington DC. American Psychiatric Association, 1987.

11. Cohen J. A coefficient of agreement for nominal scales: educational and psychological measurement. 1960:37-46.

12. Daniel WW. Biostatistics:a foundation for analysis in the health sciences. 5.Ed. New York \& John Wiley-Sons, 1991.

13. Andersen SM, Harthorn BH. Changing the psychiatric knowledge of primary care physicians: the effects of a brief intervention on clinical diagnosis and treatment. Gen Hosp Psychiatry 1990;12:177-190.

14. Crawshaw R. Second thoughts: thoughts about diagnosis. J Clin Epidemiol 1990;43:723-725.

15. Monney C. Contribution à l'approche de la "normalité": étude des sujets dits "normaux" consultant la Policlinique Psychiatrique Universitaire de Lausanne de 1957 à 1979. Schweiz Arch Neurol Psychiatr 1990;141:149-162.

16. Koponen H, Stenback LHU, Riekkinen PJ. Acute confusional states in the elderly:a radiological evaluation. Acta Psychiatr Scand 1987;76:726-731.

17. Koponen H, Stenbäck U, Mattila E, Reinikainen K, Soininen H, Riekkinen PJ. Cerebrospinal fluid somatostatin in delirium. Psychol Med 1989;19:605-609.

18. Koponen H, Reinikainen K, Riekkinen PJ. Cerebrospinal fluid somatostatin in delirium: changes at the acute stage and at one year follow-up. Psychol Med 1990;20:501-505.

19. Freudenburg WR. Perceived risk, real risk:social science and the art of probabilistic risk assessment. Science1988;242:44-49.

20. Moskowitz AJ, Kuipers BJ, Kassirer JP. Dealing with uncertainty, risks and tradeoffs in clinical decisions: a cognitive science approach. Ann Intern Med 1988;108:435-449.

21. Birley JLT. DSM-III :from left to right or from right to left ? Br J Psychiatry 1990;157:116-118.

22. Kane FJ Jr, Remmel R, Moody S. Recognizing and treating delirium in patients admitted to general hospitals. South Med J 1993;86 :985-988. 
23. Pompei P, Cassel CK. Delirium in hospitalized elderly patients. Hosp Pract 1993;28:69-76.

24. Inouye SK, Viscoli CM, Horwitz RI, Hurst LD, Tinetti ME. A predictive model for delirium in hospitalized elderly medical patients based on admission characteristics.Ann Intern Med 1993;119:474-481.

25. Liptzin,B, Levkoff SE, Cleary PD, et al. An empirical study of diagnostic criteria for delirium. Am J Psychiatry 1991;148:454-457.

26. Tueth MJ ,Cheong JA. Delirium:diagnosis and treatment in the older patient. Geriatric.1993;48:75-80.

27. Inouye SK, van Dick CH, Alessi CA, Balkin, Siegal AP, Horowitz RI. Clarifying confusion:the confusion assessment method. A new method for detection of delirium. Ann Intern Med 1990;113:941-948.

28. Norman GR, Patel VL, Schmidt HG. Clinical inquiry and scientific inquiry. Med Educ 1990;24:396-399.

29. Dundridge TC, Edwards F, Edwards RG, Atkinson M. Evaluation of benefits of screening tests done immediately on admission to hospital. Clin Chem 1976;22:968-971.

30. Griner PF. Use of laboratory tests in a teaching hospital long-term trends: reductions in use and relative cost. Ann Intern Med 1979;90:243-248.

31. Martin AR, Wolf MA, Thibodeau Laq A, Dzau V, Braunwald E. A trial of two strategies to modify the test-ordering behavior of medical residents. N Engl J Med 1980;303:1330-1336.

32. Thurow LC. Learning to say "no". N Engl J Med 1984;311;1569-1572.

33. Kassirer JP. Our stubborn quest for diagnostic certainty:a cause of excessive testing. N Engl J Med 1989;320:1489-1491.

34. Kassirer JP, Kopelman RI. The probability of a probability. Hosp Pract 1990;25:23-28.

35. Black WC, Ling A. Is earlier diagnosis really better? The misleading effects of lead time and length biases. AJR 1990;155:625-630.

36. Gifford DR, Mittman BS, Vickrey BG. Diagnostic reasoning in neurology. Neurol Clin 1996;14 :223-238.

37. Francis J, Martin D, Kapoor WN. A prospective study of delirium in hospitalized elderly. JAMA 1990;263:1097-1101.

38. Kolbeinsson H, Jonsson A. Delirium and dementia in acute medical admissions of elderly patients in Iceland.-Acta Psychiatr Scand 1993;87:123-127.

39. Cole MG, Primeau FJ. Prognosis of delirium in elderly hospital patients. Can Med Assoc J 1193;149:41-46.

40. Koponen HJ, Riekkinen PJ. A prospective study of delirium in elderly patients admitted to a psychiatric hospital.-Psychol Med 1993;23:103-109.

41. Farrell KR, Ganzini L. Misdiagnosing delirium as depression in medically ill elderly patients. Arch Intern Med 1995; 155:2459-2464.

42. Kishi Y, Iwasaki Y, Takezawa K, Kurosawa H, Endo S. Delirium in critical care unit patients admitted through an Emergency room. Gen Hosp Psychiatry 1995;17:371-379. 